\title{
Interstitial deletion, del(4)(q12q21.1), owing to de novo unbalanced translocation in a 2 year old girl: further evidence that the piebald trait maps to proximal $4 \mathrm{q} 12$
}

Institute of Medical Genetics, University of Zürich, Rämistrasse 74, CH-8001 Zürich, Switzerland A Schinzel L Brecevic F Dutly

F Binkert

Department of Paediatrics, University of Zürich, Steinwiesstrasse 75, CH-8032 Zürich, Switzerland C P Braegger

Correspondence to: Professor Schinzel.

Received 21 January 1997 Revised version accepted for publication 7 March 1997

\author{
Albert Schinzel, Christian P Braegger, Lukrecija Brecevic, Fabrizio Dutly, Franz Binkert
}

\begin{abstract}
A very short, microcephalic, and mentally retarded 2 year old girl showed minor anomalies including prominent occiput, delayed closure of the anterior fontanelle, high frontal hairline, prominent ears, upward slanting palpebral fissures, a small nose with bulbous tip, delayed tooth eruption and bone maturation, and short and tapering fingers and toes. She did not have a white forelock. Cytogenetic investigation disclosed a de novo unbalanced translocation between chromosomes 4 and 18 with deletion of $4 q 12 \rightarrow q 21.1$. Molecular investigation showed lack of a paternal allele for the microsatellite markers D4S392 and D4S398. This case shows indirect evidence that the piebald gene maps to proximal 4q12.

(F Med Genet 1997;34:692-695)
\end{abstract}

Keywords: chromosome deletion 4q; piebald trait; unbalanced translocation

Interstitial deletion of the segments $4 \mathrm{q} 11 \mathrm{q} 21$ or $4 \mathrm{q} 12 \mathrm{q} 21$ has been reported in eight patients, ${ }^{1-8}$ five of whom showed the piebald trait, a white forelock. ${ }^{12468}$ Beyond this rather unusual finding, they did not share a striking common pattern of dysmorphism and malformations.

We report clinical, cytogenetic, and molecular findings of another patient with an interstitial deletion of 4q12q21.1. She did not show the piebald trait and, in contrast to all but one ${ }^{1}$

mother on day seven after delivery. Subsequently, she suffered from episodes of colicky abdominal pain and abdominal distension of unknown aetiology. Motor and mental development were delayed with sitting at 8 to 9 months and standing at 16 months.

Clinical examination at the age of 19 months showed length $68 \mathrm{~cm}(<<3$ rd centile, approximately $-4 \mathrm{SD})$, weight $7.5 \mathrm{~kg}(<<3$ rd centile, approximately $-3.5 \mathrm{SD})$, OFC $45.5 \mathrm{~cm}$ (3rd-10th centile). Clinical dysmorphological evaluation disclosed the following abnormalities: prominent occiput, anterior fontanelle still patent $2 \times 2 \mathrm{~cm}$, high frontal hairline, prominent ears (ear length $4.7 \mathrm{~cm}$, about the 10th centile), upward slanting palpebral fissures, small nose with bulbous tip, delayed eruption of teeth (first at 18 months, at present only two lower and one upper incisor erupted), barrel chest, prominent abdomen, short and tapering fingers (total hand length $8.4 \mathrm{~cm}$, below the 3rd centile), rocker bottom feet, and short and broad toes. On external examination, there were no other abnormalities; cardiac auscultation indicated a 1-2/6 systolic murmur which was considered to be only functional. No hypo- or hyperpigmented areas of the skin wer visible.
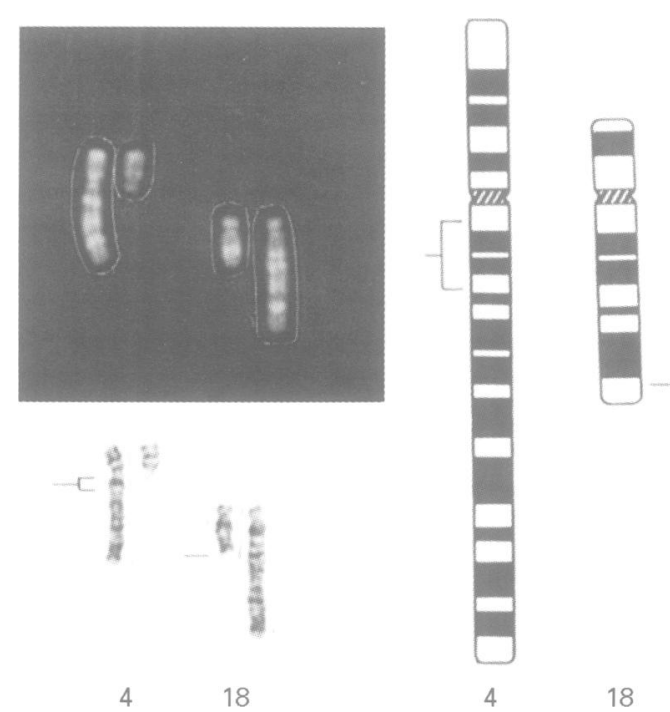

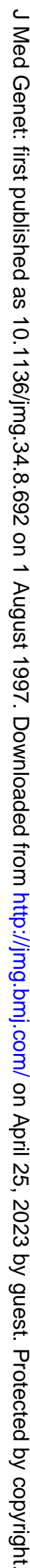
but at delivery there was only mild asphyxia. Birth weight was $2700 \mathrm{~g}$ and length was $45 \mathrm{~cm}$. No special features were initially noticed in the infant and so she was discharged with her
Figure 1 Chromosomes 4 and 18 from one RFA and are indicated by arrows on the normal homologues of the GTG banded karyotype and the diagram. GTG banded metaphase each of the proband. Breakpoints 

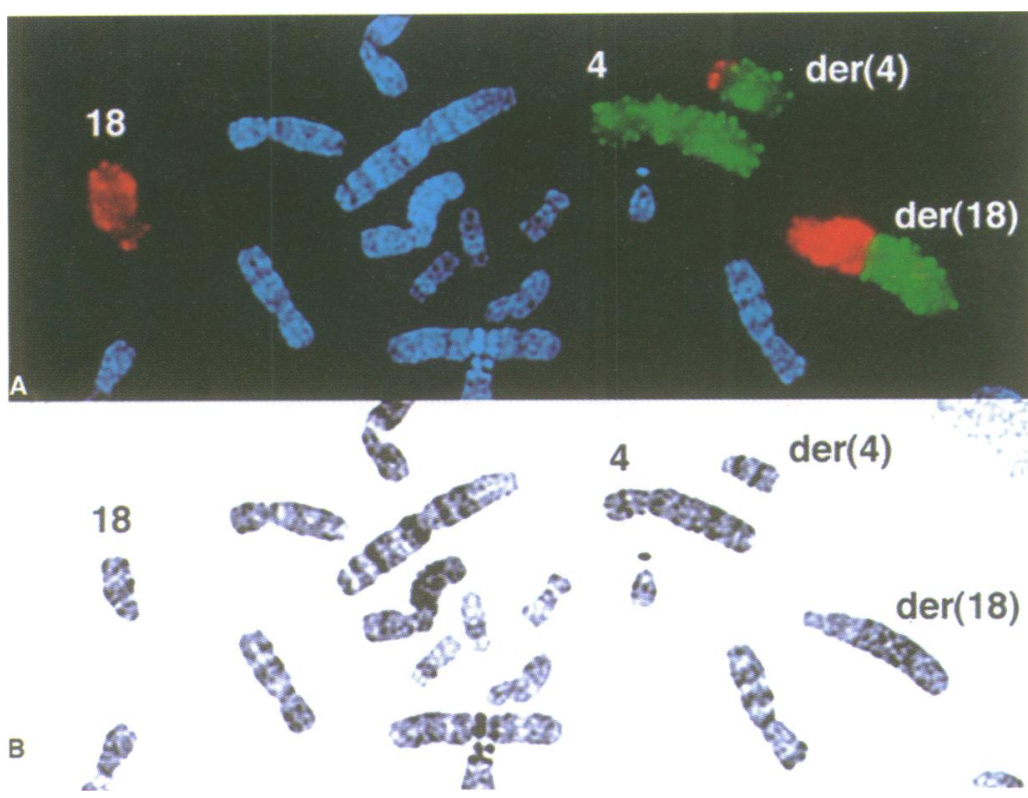

Figure 2 Dual colour FISH of a metaphase of the proband $(A)$ with GTG banded control (B). Chromosome 4 is painted in green, chromosome 18 in red. Note the reciprocal translocation with a large segment of chromosome 4 attached to chromosome 18 and a tiny segment of chromosome 18 attached to chromosome 4.

\section{FURTHER INVESTIGATIONS}

Histological analysis of a duodenal biopsy specimen showed ectatic vessels, but otherwise normal findings, and histological examination of a colonic biopsy showed normal findings. Thus, the gastrointestinal problems were considered to be the result of aerophagia.

Radiographs of the lumbar and sacral vertebral column and pelvis were normal. Hand $x$ rays showed normal bones but severe delay in carpal (9/12) and phalangeal (12/12) bone ages at a chronological age of 24 months.

CYTOGENETIC INVESTIGATIONS

GTG and RFA banded metaphases from lymphocyte chromosome cultures showed an unbalanced translocation between chromosomes 4 and 18 with presumed loss of the segment (4)(q12 $\rightarrow \mathrm{q} 21.1): 46, \mathrm{XX}, \mathrm{t}(4 ; 18)$ (4pter $\rightarrow$ 4q12::18q23 $\rightarrow$ 18qter; 18pter $\rightarrow 18 \mathrm{q} 23$ $:: 4 q 21.1 \rightarrow 4 q t e r$ ) (fig 1). Chromosome painting with libraries of chromosome 4 (digoxigenised, red) and chromosome 18 (biotinilated, green) showed the reciprocity of the translocation and excluded involvement of a third chromosome (fig 2). Parental karyotypes were normal. No cell line of the proband is available.

\section{MOLECULAR INVESTIGATIONS}

The results of microsatellite marker analysis of loci within the segment $4 \mathrm{q} 12 \rightarrow \mathrm{q} 21$ are pre-

Table 1 Results of microsatellite examination for chromosome $4 q$ in the proband and her parents. All primers were obtained from Research Genetics

\begin{tabular}{lll}
\hline Primer & Locus & Alleles \\
\hline D4S398 & 4q13-q21 & d,cd,ab \\
D4S399 & 4q13-q21 & aa,aa,ab \\
D4S392 & 4q13-q21 & a,aa,bc \\
D4S247 & 4q26-q27 & ac,cc,ab \\
D4S427 & 4q26-q27 & ac,ac,bc \\
D4S175 & 4q26-q27 & bc,cc,ab \\
\hline
\end{tabular}

The alleles are given in the order: patient, mother, father. Th markers showing paternal deletion are given in bold. Allele designations (a to d) are arbitrary. sented in table 1 and fig 3. Control markers at $4 \mathrm{q} 26 \rightarrow \mathrm{q} 27$ were analysed in order to exclude maternal uniparental disomy 4. For markers D4S392 and D4S398, the proband had inherited one of the two maternal alleles, but lacked either of the two paternal alleles; marker D4S399 was not informative. The three markers on distal $4 \mathrm{q}$ showed normal biparental inheritance in the proband. Thus, the combined results confirmed the interstitial deletion of proximal $4 \mathrm{q}$, disclosed its paternal origin, and excluded maternal uniparental disomy of chromosome 4.

\section{Discussion}

Interstitial deletion of the segment $4 \mathrm{q} 12 \rightarrow \mathrm{q} 21.1$, as was found in the proband, has so far only rarely been reported. In one case reported in the early banding period (1977), ${ }^{2}$ the proximal breakpoint was determined at $4 \mathrm{q} 11$, while in five others, ${ }^{13-8}$ it was in $4 \mathrm{q} 12$. Owing to a less precise determination of breakpoints in the seventies, it is possible that the breakpoints did not differ and that the former case also had the proximal breakpoint at $4 \mathrm{q} 12$. Only in the four latter cases was the distal breakpoint found to be within 4q21, specifically in its proximal segment, at $4 \mathrm{q} 21.1^{4-7}$; $4 \mathrm{q} 21.1$ was also the breakpoint in our proband.

A comparison of the clinical findings in the eight previously reported patients with the proband of this report is presented in table 2 .
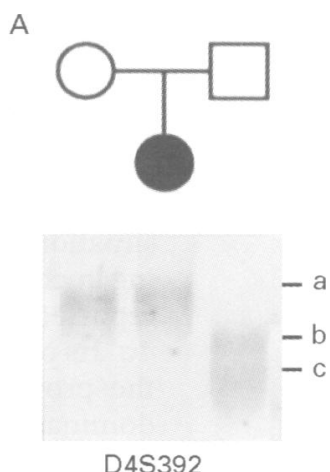

B
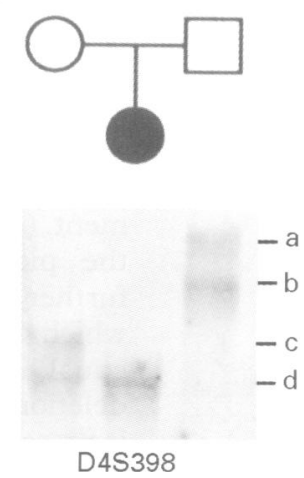

Figure 3 Results of microsatellite marker analysis for D4S392 (A) and D4S398 (B) in the proband and her parents showing absence of a paternal allele. DNA extracted from peripheral blood was amplified on a pe 9600 with 32 cycles of 30 seconds at $94^{\circ} \mathrm{C}, 45$ seconds at $55^{\circ} \mathrm{C}$ for annealing, and one minute 20 seconds at $72^{\circ} \mathrm{C}$ for extension. The reaction products were loaded onto a polyacrylamide/urea gel. Visualisation of the bands was done by silver staining. 
Table 2 Clinical findings in reported patients with deletion of $(4)(q 11 \rightarrow q 21)$ or (4) (q12 $\rightarrow q 21)$. Except for major malformations, only findings present in at least two patients were considered

\begin{tabular}{|c|c|c|c|c|c|c|c|c|c|c|}
\hline \multirow[b]{2}{*}{ Findings } & \multicolumn{8}{|c|}{ Reference } & \multirow{2}{*}{$\begin{array}{l}\text { Our } \\
\text { patient }\end{array}$} & \multirow[b]{2}{*}{$n=9$} \\
\hline & 1 & 2 & 3 & 4 & 5 & 6 & 7 & 8 & & \\
\hline Deleted segment (see footnote) & a & b & a & c & c & c & c & c & c & - \\
\hline Age at last examination $(\mathrm{y} / \mathrm{mth})$ & $3 / 6$ & $1 / 0$ & $4 / 0$ & $6 / 6$ & $1 / 8$ & $0 / 7$ & $3 / 10$ & $4 / 0$ & $2 / 0$ & - \\
\hline Short stature & + & $?$ & + & + & + & - & $?$ & + & + & $6 / 7$ \\
\hline \multicolumn{11}{|l|}{ Craniofacial } \\
\hline Macrocephaly/microcephaly & $-1-$ & $?$ & $-1-$ & $-1+$ & $+/-$ & $-1-$ & $-1+$ & $-/+$ & $-/+$ & $1 / 4$ \\
\hline Prominent forehead & - & $?$ & + & + & + & $?$ & $?$ & - & - & $3 / 6$ \\
\hline High frontal hairline & $?$ & $?$ & + & $?$ & + & $?$ & $?$ & + & + & $4 / 4$ \\
\hline Upward slanting palpebral fissures & - & $?$ & + & $?$ & - & $?$ & $?$ & $?$ & + & $2 / 4$ \\
\hline Epicanthic folds & - & + & + & $?$ & + & $?$ & - & - & - & $3 / 7$ \\
\hline Depressed nasal bridge & - & + & + & - & + & + & - & - & - & $4 / 8$ \\
\hline Delayed tooth eruption & + & $?$ & $?$ & + & $?$ & $?$ & $?$ & $?$ & + & $3 / 3$ \\
\hline Low set ears & - & + & + & + & - & $?$ & - & + & - & $4 / 8$ \\
\hline \multicolumn{11}{|l|}{ Genitalia } \\
\hline Hypospadias & - & $\emptyset$ & 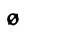 & + & - & - & - & 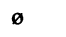 & $\varnothing$ & $1 / 5$ \\
\hline Cryptorchidism & - & $\emptyset$ & D & + & - & - & - & ø & $ø$ & $1 / 5$ \\
\hline \multicolumn{11}{|l|}{ Limbs } \\
\hline Small hands and feet & $?$ & $?$ & + & $?$ & + & $?$ & $?$ & + & + & $4 / 4$ \\
\hline Clinodactyly 5 & + & + & - & $?$ & - & $?$ & - & + & - & $3 / 7$ \\
\hline Transverse palmar creases & - & + & $?$ & - & + & ? & $?$ & $?$ & - & $2 / 5$ \\
\hline \multicolumn{11}{|l|}{ Malformations } \\
\hline Coloboma of iris/optic nerve & - & - & - & - & - & - & + & - & - & $1 / 9$ \\
\hline Microphthalmia & - & - & - & - & - & - & + & - & - & $1 / 9$ \\
\hline Renal agenesis & - & - & - & - & - & + & - & - & - & $1 / 9$ \\
\hline \multicolumn{11}{|l|}{ CNS } \\
\hline Seizures & - & - & + & + & - & - & - & - & - & $2 / 9$ \\
\hline Hypotonia & + & $?$ & + & + & + & $?$ & + & $?$ & + & $6 / 6$ \\
\hline Mental retardation & + & + & + & + & + & + & + & + & + & 9/9 \\
\hline Piebald trait & + & + & - & + & - & + & - & + & - & $5 / 9$ \\
\hline
\end{tabular}

This analysis shows that, as is often the case in interstitial deletions, ${ }^{9}$ the pattern of abnormalities is not very striking and thus, in contrast to many terminal autosomal deletions with a rather abnormal phenotype, it would hardly be possible to recognise the specific deletion in such a patient from the clinical findings alone. However, if multiple minor anomalies and growth and mental retardation are present in a patient with a white forelock (piebald trait), the situation is different: the latter is a unique finding in chromosome aberrations, ${ }^{9}{ }^{10}$ having been reported so far only in proximal deletions of 4q. Its occurrence in the first two case ${ }^{12}{ }^{2}$ led to the provisional mapping of the gene for the dominant piebald trait to the deleted region $4 \mathrm{q} 12 \rightarrow \mathrm{q} 21.1$. However, lack of a white forelock in 4/9 patients (including ours) with a deletion including $4 \mathrm{q} 12 \rightarrow \mathrm{q} 21.1$ leaves several explanations open. First, the proximal breakpoint could be different in the patients with and without a white forelock, being more proximal and thus including the "piebald gene" in the former group. Evidence for this explanation is a case with an overlapping, but more distal $4 \mathrm{q}$ deletion which includes the segment $(4)(\mathrm{q} 13 \rightarrow \mathrm{q} 22)$ in which no features of the piebald trait were found. ${ }^{11}$ Second, a further controlling gene might be involved which would have two alleles of approximately equal incidence, restoring the effect of the deletion of the piebald gene if one of the alleles is present. This explanation is not very likely as it would imply that the penetrance of the piebald trait would be well below $50 \%$ which is not the case, at least not if associated findings (heterochromia of the iris, deafness, Hirschsprung disease, epitheliomas) are also considered. Third, it could also be speculated that occurrence of the piebald trait in half of the patients with interstitial deletions with a proxi- mal breakpoint at $4 \mathrm{q} 12$ indicates gene disruption or gene deletion. This might suggest again that the action of this gene is not through haplotype insufficiency but rather through a distorted gene product. A fourth explanation would be that the white forelock was either not yet present in the "negative" cases or was overlooked. As these patients were not the younger ones (table 2) and did not in general show depigmentation, this is also not very likely. Thus, it seems probable that the gene for piebald trait maps to proximal 4q12 and was either deleted or disrupted in only a proportion of cases with $\operatorname{del}(4)(\mathrm{q} 12 \rightarrow \mathrm{q} 21)$ while the breakpoint in the others, including our proband, was outside and probably distal to this gene.

The intestinal problems in the proband could not be clarified by an intestinal and colonic biopsy; it is noteworthy that the same kinds of problem were reported in two previous patients with a similar deletion: frequent regurgitation ${ }^{35}$ and tympanitic abdomen, feeding difficulties, and frequent vomiting. ${ }^{5}$ The latter patients did not show the pigmentary changes of the piebald trait. Hirschsprung disease resulting from aganglionic colon as one feature of piebald trait was excluded in our proband, but not in the two other patients. Therefore, although such problems are not uncommon in patients with chromosome aberrations and other MCA/MR syndromes, they might also represent a feature of as yet unknown pathogenesis of this particular deletion.

The authors are grateful to the parents of the proband for their cooperation. The work was supported by the Swiss National Foundation, grant No 32.37798.93.

1 Funderburk SJ, Crandall BF. Dominant piebald trait in a retarded child with a reciprocal translocation and smal intercalary deletion. Am 7 Hum Genet 1974;26:715-22. 
2 Lacassie Y, Thurmon TF, Tracy MH, et al. Piebald trait in a retarded child with interstitial deletion of chromosome 4 Birth Defects 1977;13:247.

3 Lech $\mathrm{H}$, Kubalska J, Wisniewski L. The child with congenital anomalies and interstitial deletion of the long arm of chromosome 4. Klin Padiatr 1982;194:117-19.

4 Hoo JJ, Haslam RHA, van Orman C. Tentative assignment of piebald trait gene to chromosome band 4q12. Hum Genet 1986;73:230-1.

5 Beall MH, Falk RE, Ying KL. A patient with an interstitial deletion of the proximal portion of the long arm of deletion of the proximal portion of the long
chromosome 4. Am $\mathcal{F}$ Med Genet 1988;31:553-7.

6 Yamamoto Y, Nishimoto H, Ikemoto S. Interstitial deletion of the proximal long arm of chromosome 4 associated with father-child incompability within the Gc-system: probable father-child incompability within the Gc-system: probable
reduced gene dosage effect and partial piebald trait. $A m \mathcal{F}$
Med Genet 1989;32:520-3.
7 Curtis MA, Quarrell OWJ, Cobon AM, et al. Interstitial deletion of chromosome 4, $\operatorname{del}(4)(\mathrm{q} 12 \mathrm{q} 21.1)$, in a child with multiple congenital abnormalities. F Med Genet 1990; 27:64-5.

8 Sijmons $\mathrm{RH}$, Kristoffersson U, Tuerlings JHAM, Ljung B, Dijkhuis-Stoffelsma $R$, Breed APSM. Piebaldism in a men-
tally retarded girl with rare deletion of the long arm of chromosome 4. Pediatr Dermatol 1993;10:235-9.

9 Schinzel A. A catalogue of unbalanced chromosome aberrations in man. Berlin: Walter de Gruyter, 1984.

10 Schinzel A. Human cytogenetics database. Oxford Medical Databases Series. Oxford: Oxford University Press, Electronic Publishing, 1994.

11 McDermott A, Cain R, Howell R. Partial monosomy of long arm of chromosome 4 due to interstitial deletion. Hum Genet 1980;53:305-7. 